Polymer Journal, Vol. 39, No. 10, pp. 1040-1046 (2007)

(C)2007 The Society of Polymer Science, Japan

\title{
Biocompatible Hydrogel Formation of Gelatin from Cold Water Fish via Enzymatic Networking
}

\author{
Young-Jin KIM ${ }^{1}$ and Hiroshi UYAmA ${ }^{2, \dagger}$ \\ ${ }^{1}$ Department of Biomedical Engineering, Catholic University of Daegu, \\ 330 Geumnak 1-ri, Hayang-eup, Gyeongsan, Gyeongbuk 712-702, Korea \\ ${ }^{2}$ Department of Applied Chemistry, Graduate School of Engineering, Osaka University, Suita 565-0871, Japan
}

(Received April 11, 2007; Accepted July 2, 2007; Published August 21, 2007)

\begin{abstract}
Biocompatible hydrogel formation of gelatin from cold water fish skin has been examined using enzyme catalyst. Due to the large number of functional groups in the side chain, gelatin readily undergoes chemical crosslinking, which is important for its possible use as biomaterial. In addition, transglutaminase (TGase) provides an alternative method for creating a gelatin gel and may offer interesting opportunities as injectable material for various applications. The aim of this study was to investigate the effect of the reaction conditions on rheological and mechanical properties of the hydrogels in the enzymatic curing of gelatin from cold water fish skin. The rheological measurements showed that TGase catalyzed the transformation of gelatin solutions into hydrogels, and the gel points were between 3.3 and 144 min depending on the concentration of gelatin and TGase. Furthermore, the buffer $\mathrm{pH}$ strongly affected the rheological properties. Mechanical tests of the resulting hydrogels exhibited that the elastic modulus ranged from 21 to $292 \mathrm{kPa}$, which were influenced by the concentrations of gelatin and TGase. The rheological and mechanical properties of the gelatin gels were closely related to the degree of the crosslinking. [doi:10.1295/polymj.PJ2007007] KEY WORDS Crosslinking / Enzyme / Gelatin / Hydrogel / Transglutaminase /
\end{abstract}

Gelatin is a biopolymer obtained by thermal denaturation or physical and chemical degradation of native collagen, which are the most widespread structural protein in the body occurring in most connective tissues such as skin, tendon and bone. ${ }^{1}$ The present wide interest in gelatin is mainly due to merits of wealth like biological origin, nonimmunogenicity, biodegradability and biocompatibility. Gelatin has been the most frequently used in the biomedical and pharmaceutical fields including hard and soft capsules, microspheres, sealants for vascular prostheses, wound dressing and adsorbent pad for surgical use. ${ }^{2}$ Most of commercial gelatins are obtained from either pigskin or cowhide, and especially, the use of bovine gelatin has been limited because of the risks of bovine spongiform encephalopathy (BSE), which is considered to be transmittable to human beings. Therefore, there has been the increasing interest in nonmammalian gelatin sources, primarily fish gelatin. ${ }^{3}$ It seems that fish gelatin has lower risk for transmission of infectious diseases to human beings than bovine gelatin.

The source and type of collagen will influence the properties of gelatin. The amino acid content and sequence vary from one source to another, but gelatin always consists of large amounts of proline, hydroxyproline and glycine. The gelling properties of gelatin are affected mainly by the origin of raw material. This results from difference in contents of proline and hydroxyproline in collagens of different species and is connected with the temperature of the habitat of the animals. ${ }^{4}$ The thermal shrinkage, denaturation temperature and melting temperature of gelatins derived from the skins of cold water fishes are significantly lower than those of gelatins from skins of warmblooded animals and fishes living in warm water, due to the lower hydroxyproline content. ${ }^{4,5}$ This property results in the limitation of their applications for biomaterials.

Hydrogels are composed of a three-dimensional hydrophilic polymer network in which a large amount of water is interposed. Due to their unique properties, a wide range of medical, pharmaceutical and prosthetic applications have been proposed. ${ }^{6}$ Hydrogels derived from naturally occurring polymers mimic many features of extracellular matrix and thus have the potential to direct the migration, growth and organization of cells during tissue regeneration and wound healing. Stimulus-responsive gel formation of biopolymers offers promising prospects for bio-related applications of wide engineering fields and injectable system of biopolymer hydrogels are highly potent for biomaterials.

So far, the stimulus-responsive gelation of biopolymers has been achieved by thermal sol-gel transition, photo-polymerization, enzymatic crosslinking, and chemical crosslinking with metal ions or crosslinking agents. $^{7}$ The photo-polymerization requires a photosensitizer and prolonged irradiation, resulting in limit-

${ }^{\dagger}$ To whom correspondence should be addressed (Tel: +81-6-6879-7364, Fax: +81-6-6879-7367, E-mail: uyama@ chem.eng.osaka-u.ac.jp). 
ing their use. The crosslinking with metal ions is often reversible in the body and exerts cytotoxic effects. ${ }^{8}$ In the chemical crosslinking, crosslinking agents such as glutaraldehyde and isocyanates which incorporated into the polymer matrix are highly toxic and are prone to leach out into the body on matrix biodegradation. ${ }^{9}$ The toxicity of the crosslinking agents is the major obstacle in the use of these biopolymers as an injectable since their seepage into body fluids even at low concentrations can be very hazardous. ${ }^{10}$ Potentially less toxic reagents like adipic acid dihydrazide and oxidized mono-, di- and polysaccharides have been investigated as crosslinking agents. ${ }^{11}$ However, the gelation reaction is rather slow to be of practical use as an injectable.

Transglutaminase (TGase) catalyses an acyl transfer reaction that leads to the formation of crosslinking isopeptide bonds between $\gamma$-carboxyamide groups of glutamyl residue and $\varepsilon$-amino groups of lysine residue. ${ }^{12}$ This reaction causes substantial changes in the functional properties of plant and animal proteins with improved rheological properties. ${ }^{13}$ In mammalian cells, TGases are calcium-dependent and appear to serve various roles such as fibrin polymerization in blood clotting. ${ }^{14}$ The discovery of a calcium-independent microbial TGase has stimulated research for a variety of applications especially in the food industry. ${ }^{15}$

Recently, it was reported that the enzymatic crosslinking of gelatin proceeded in the presence of TGase. ${ }^{16}$ In the standpoint of toxicity of the crosslinking agent, it may be useful to crosslink gelatin with non-toxic enzyme catalyst. This study deals with the biocompatible hydrogel formation of gelatin from cold water fish skin with microbial TGase (Scheme 1). We have systematically examined the enzymatic curing of fish gelatin for the first time. The effect of the reaction conditions on the rheological properties of the resulting gelatin gels was investigated in detail. Additionally, the mechanical properties of the gelatin gels were examined.

\section{EXPERIMENTAL}

\section{Materials}

Teleostean gelatin from cold water fish skin (type A) was purchased from Sigma Chemical and used without further purification. The calcium-inde-

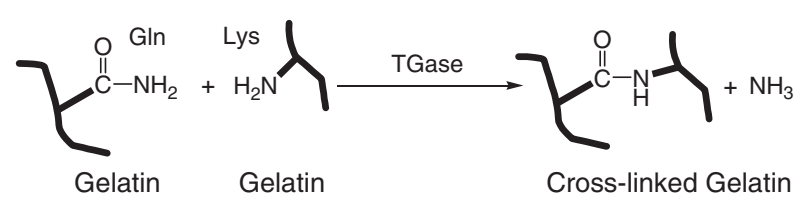

Scheme 1. pendent microbial transglutaminase (TGase, Activa TR) derived from Streptoverticillium monobaraense was kindly supplied by Ajinomoto Co., Inc. 2,4,6-Trinitro-benzensulfonic acid (TNBS) was obtained from Wako Pure Chemicals Industries, Ltd. Other reagents and solvents were commercially available and were used as received.

\section{Enzymatic Curing of Gelatin}

The gelatin gel was prepared as follows. Gelatin was dissolved in $0.1 \mathrm{M}$ phosphate buffer $(\mathrm{pH} 7.0)$, at a concentration in the range of $10-40 \mathrm{w} / \mathrm{v} \%$ and left for a day at $37^{\circ} \mathrm{C}$. Then, an enzyme solution of TGase $(10 \mathrm{w} / \mathrm{v} \%)$ in $0.1 \mathrm{M}$ phosphate buffer was added at $37^{\circ} \mathrm{C}$ to initiate the crosslinking of gelatin.

\section{Measurement of Rheological Properties}

The rheological properties were measured using a Thermohaake RheoStress 1 rheometer (Thermo Electron Co.) equipped with a $35 \mathrm{~mm}$ diameter parallel plate sensor (PP35 Ti) at $37^{\circ} \mathrm{C}$. After mixing gelatin and TGase, the solution was immediately loaded on the top of the bottom plate, and the measurement was initiated soon after the parallel plate was lowered onto the sample with a gap distance of $0.5 \mathrm{~mm}$. The samples were subjected to an oscillatory stress of $0.5 \mathrm{~Pa}$ at a frequency of $0.1 \mathrm{~Hz}$ and the corresponding moduli were measured. To limit the evaporation of water during the measurements, the parallel plate was covered with low viscosity silicon oil.

\section{Compressive Mechanical Testing}

The mechanical properties of the gelatin gels were characterized by universal testing machine, EZ Graph (Shimadzu Co.). The samples were prepared by mixing TGase with gelatin solutions. After adding TGase, the solutions poured into a Teflon dish sealed with a glass lid and allowed to undergo crosslinking at $37^{\circ} \mathrm{C}$ for $12 \mathrm{~h}$. Then, the cross-linked samples were cut into discs $(16 \mathrm{~mm}$ in diameter and $5 \mathrm{~mm}$ in thickness) and compressed perpendicularly by two metal platens connected to a load cell, at a strain rate of $10 \% / \mathrm{min}$ at room temperature.

\section{Determination of the Degree of Crosslinking}

The degree of crosslinking was determined according to the reported method. ${ }^{17}$ To a sample of $3-5 \mathrm{mg}$ of the gelatin gel, $1 \mathrm{~mL}$ of $4 \mathrm{w} / \mathrm{v} \% \mathrm{NaHCO}_{3}$ solution (pH 8.5 ) and $1 \mathrm{~mL}$ of freshly prepared $0.5 \mathrm{w} / \mathrm{v} \%$ TNBS solution in distilled water were added. After the reaction at $40^{\circ} \mathrm{C}$ for $2 \mathrm{~h}, 2 \mathrm{~mL}$ of $6 \mathrm{~N} \mathrm{HCl}$ was added, and the temperature was raised to $60^{\circ} \mathrm{C}$. Solubilization of the gelatin gels was achieved within $90 \mathrm{~min}$. The resulting solution was diluted with $5 \mathrm{~mL}$ of distilled water, and the absorbance was measured 
at $345 \mathrm{~nm}$ with a Hitachi U-2810 spectrometer. The degree of crosslinking was calculated as follows:

$$
\begin{aligned}
& \text { Degree of crosslinking }(\%) \\
& =\left\{1-\left(\text { absorbance }_{\mathrm{s}} / \text { mass }_{\mathrm{s}}\right)\right. \\
& \left.\quad /\left(\text { absorbance }_{\text {ncg }} / \text { mass }_{\text {ncg }}\right)\right\} \times 100
\end{aligned}
$$

where the subscripts s and ncg denote the sample and non-cross-linked gelatin, respectively.

\section{RESULTS AND DISCUSSION}

\section{Rheological Properties of Gelatin Gels}

Rheological methods were used to characterize the dynamics of gel formation. In these experiments, a gelatin solution was mixed with TGase and immediately loaded onto a rheometer where the samples were subjected to oscillatory stresses. Results from these experiments yield two moduli. The elastic modulus $\left(\mathrm{G}^{\prime}\right)$ is related to the energy that is stored in the sample to resist deformation and is a measure of the strength of the gel. The viscous modulus $\left(\mathrm{G}^{\prime \prime}\right)$ is a measure of the energy that is dissipated when the sample is deformed.

Initial studies to explore TGase-catalyzed gel formation were conducted by loading 10 and $40 \%$ gelatin solutions onto a rheometer and following changes in properties over time. Figure 1 shows typical results for samples prepared from cold water fish skin gelatin. At $37^{\circ} \mathrm{C}$, the samples behaved as solutions with $\mathrm{G}^{\prime \prime}$ higher than $G^{\prime}$ immediately after mixing TGase with gelatin. As shown in Figure 1, both moduli increased with time and $\mathrm{G}^{\prime}$ increased more rapidly and became equal to $\mathrm{G}^{\prime \prime}$ after 17.1 and $3.3 \mathrm{~min}$ for the 10 and $40 \%$ gelatin solutions, respectively. The point at which $\mathrm{G}^{\prime}$ becomes equal to $\mathrm{G}^{\prime \prime}$ is typically used as a rheological measure of the gel point. ${ }^{18}$ After the gel point, both moduli continued to increase in the gel state of gelatin. These results indicate that TGase catalyzed the conversion of gelatin solutions into gels. These gels formed as a result of the covalent crosslinking of the gelatin chains and differ from the thermally reversible physical gelatin gels that are formed by cooling. Furthermore, the network structure of the present gelatin gels was not destroyed by the heating treatment at $60{ }^{\circ} \mathrm{C}$ for $48 \mathrm{~h}$.

To examine the effect of the TGase concentration on the gel formation, a series of rheological tests was performed with samples containing different TGase concentration in 10 and $30 \%$ gelatin solutions. In both cases, $G^{\prime}$ of the gelatin solutions increased with time (Figure 2). As expected, the rheological properties of gelatin were affected by the concentration of TGase. $\mathrm{G}^{\prime}$ increased more rapidly with increasing the concentration of TGase. The effect of the concentration of TGase on the gel point was summarized
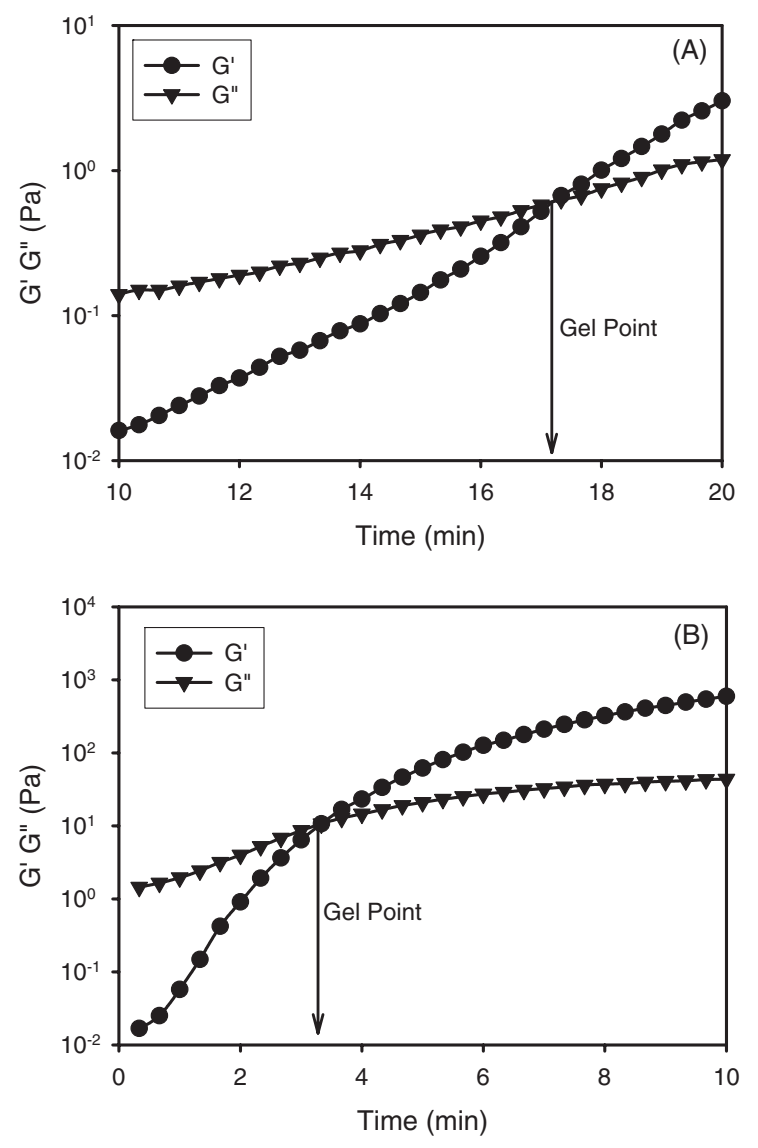

Figure 1. Rheological detection of gel formation. Elastic $\left(\mathrm{G}^{\prime}\right)$ and viscous $\left(\mathrm{G}^{\prime \prime}\right)$ moduli for gels formed from $(\mathrm{A})$ gelatin $(10 \mathrm{w} /$ $\mathrm{v} \%)$-TGase $(0.3 \mathrm{w} / \mathrm{v} \%)$ and $(\mathrm{B})$ gelatin $(40 \mathrm{w} / \mathrm{v} \%)$-TGase $(0.7 \mathrm{w} /$ $\mathrm{v} \%)$.

in Table I. The gel point was shortened with the higher concentration of TGase and was in the range from 3.3 to $144 \mathrm{~min}$. This means that the TGase-catalyzed crosslinking proceeds faster and yields stronger gels in using higher concentration of the enzyme catalyst.

We also verified the effect of the buffer $\mathrm{pH}$ on the rheological properties of gelatin solutions at $37^{\circ} \mathrm{C}$. In the case of $\mathrm{pH}$ lower than 9 , the increase of $\mathrm{G}^{\prime}$ was faster and the gel point became shorter at higher $\mathrm{pH}$ (Figure 3 and Table II). On the other hand, the further higher $\mathrm{pH}(\mathrm{pH} 10)$ slowed down the reaction of the gel formation of gelatin solutions. This result may be explained in terms of protonation and deprotonation of enzyme active site (cystein) at low and high $\mathrm{pH}$, respectively. The disruption of the active site conformation due to the enzyme denaturation at low and high $\mathrm{pH}$ also leads to the decline of enzyme activity. ${ }^{19}$

\section{Mechanical Properties of Gelatin Gels}

The mechanical properties of gelatin gels obtained with different gelatin and TGase concentrations were evaluated by compressive mechanical test. For this measurement, the gelatin solution was mixed with TGase and incubated in a Teflon dish to form hydro- 

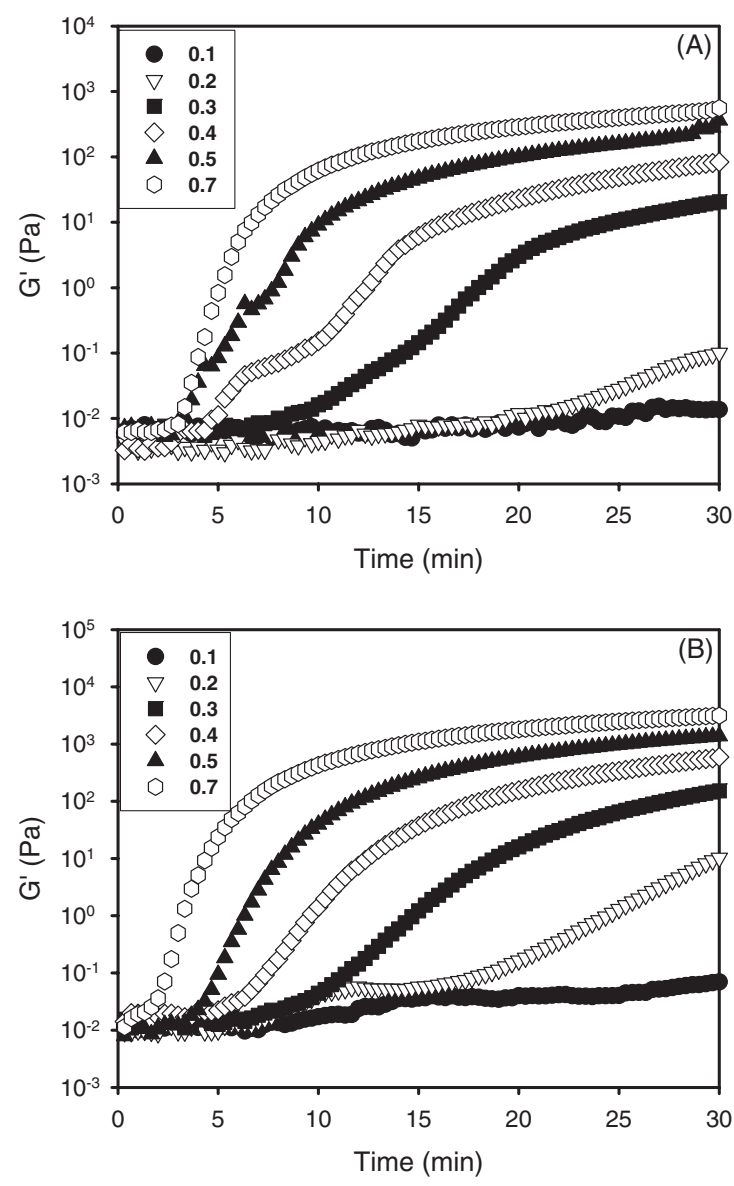

Figure 2. Effect of TGase concentration on the strength of gelatin gel formed from (A) $10 \mathrm{w} / \mathrm{v} \%$ and (B) $30 \mathrm{w} / \mathrm{v} \%$ gelatin solutions.

Table I. Gel Points of Enzyme-Catalyzed Gel Formation with Different Concentration of Gelatin and TGase ${ }^{\mathrm{a}}$

\begin{tabular}{ccccc}
\hline \multicolumn{5}{c}{ Gel Point $(\mathrm{min})^{\mathrm{b}}$} \\
\hline TGase Concentration & \multicolumn{3}{c}{ Gelatin Concentration (w/v\%) } \\
\cline { 2 - 5 }$(\mathrm{w} / \mathrm{v} \%)$ & 10 & 20 & 30 & \multicolumn{1}{c}{40} \\
\hline 0.1 & 144 & 69.2 & 38.4 & 33.7 \\
0.2 & 40.6 & 38.5 & 31.6 & 28.7 \\
0.3 & 17.1 & 14.9 & 18.2 & 20.4 \\
0.4 & 11.7 & 10.3 & 11.9 & 12.3 \\
0.5 & 5.5 & 6.3 & 7.5 & 9.2 \\
0.7 & 4.6 & 4.5 & 4.0 & 3.3 \\
\hline
\end{tabular}

${ }^{a}$ Rheological tests were performed as follows; a gelatin solution dissolved in $0.1 \mathrm{M}$ phosphate buffer $(\mathrm{pH} 7)$ was mixed with TGase and immediately loaded onto a rheometer where the samples were subjected to oscillatory stresses at $37^{\circ} \mathrm{C}$. ${ }^{\text {b }} \mathrm{Gel}$ point is the time at which $\mathrm{G}^{\prime}$ becomes equal to $\mathrm{G}^{\prime \prime}$.

gels, which were subsequently cut into specimens. Then, they were mounted in compressive test fixtures and loaded in tension at a rate $10 \% / \mathrm{min}$.

Figure 4 shows typical compressive strain-stress curves of the gelatin gels with the different gelatin concentrations. The elastic modulus $(E)$ was calculat-
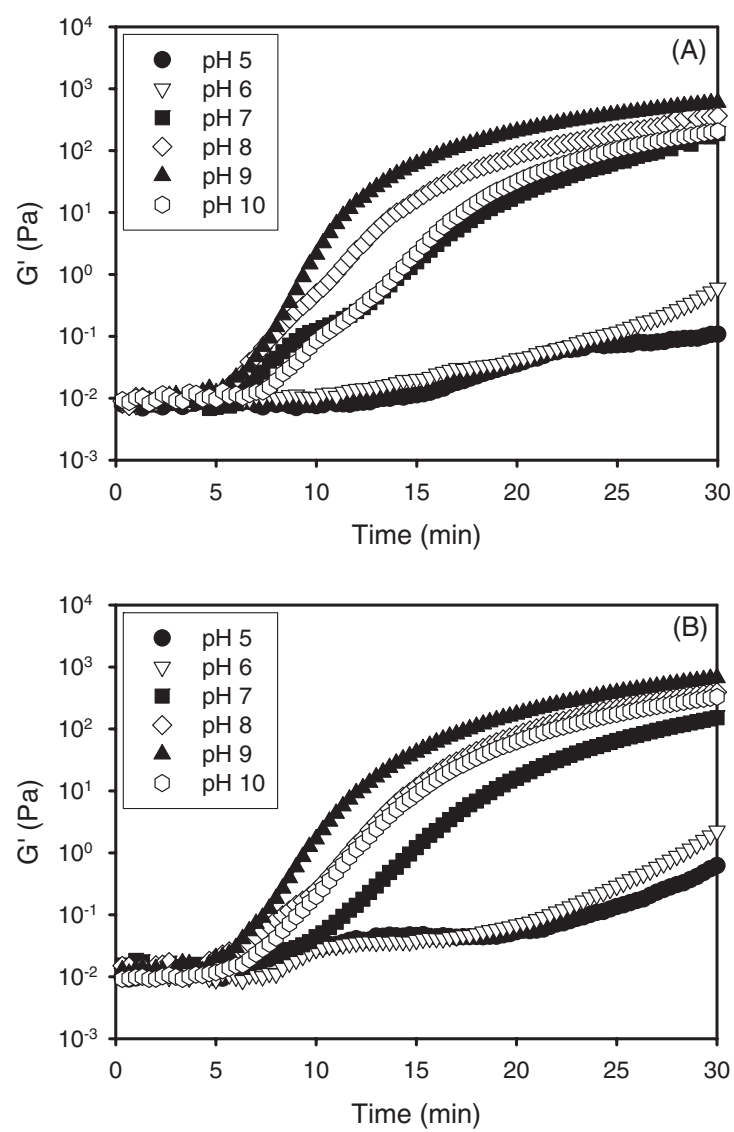

Figure 3. Effect of $\mathrm{pH}$ of buffer solution on the strength of gelatin gels formed from (A) $20 \mathrm{w} / \mathrm{v} \%$ and (B) $30 \mathrm{w} / \mathrm{v} \%$ gelatin solutions with $0.3 \mathrm{w} / \mathrm{v} \%$ TGase.

Table II. Gel Points of TGase-Catalyzed Gel Formation with Different $\mathrm{pH}$ of Buffer Solution ${ }^{\mathrm{a}}$

\begin{tabular}{|c|c|c|c|c|}
\hline \multirow{4}{*}{$\mathrm{pH}^{\mathrm{c}}$} & \multicolumn{4}{|c|}{ Gel Point $(\min )^{b}$} \\
\hline & \multicolumn{2}{|c|}{ Gelatin $20 \mathrm{w} / \mathrm{v} \%$} & \multicolumn{2}{|c|}{ Gelatin $30 \mathrm{w} / \mathrm{v} \%$} \\
\hline & TGase & TGase & TGase & TGase \\
\hline & $0.3 \mathrm{w} / \mathrm{v} \%$ & $0.5 \mathrm{w} / \mathrm{v} \%$ & $0.3 \mathrm{w} / \mathrm{v} \%$ & $0.5 \mathrm{w} / \mathrm{v} \%$ \\
\hline 5 & 45.5 & 24.7 & 37.2 & 17.4 \\
\hline 6 & 33.6 & 13.7 & 34.2 & 14.4 \\
\hline 7 & 14.9 & 6.3 & 18.2 & 7.5 \\
\hline 8 & 12.0 & 5.8 & 14.8 & 6.9 \\
\hline 9 & 10.3 & 5.4 & 11.9 & 6.0 \\
\hline 10 & 15.4 & 6.8 & 15.1 & 6.8 \\
\hline
\end{tabular}

${ }^{\mathrm{a}}$ Rheological tests were performed as follows; a gelatin solution $(20$ or $30 \mathrm{w} / \mathrm{v} \%)$ dissolved in $0.1 \mathrm{M}$ phosphate buffer was mixed with TGase $(0.3$ or $0.5 \mathrm{w} / \mathrm{v} \%)$ and immediately loaded onto a rheometer where the samples were subjected to oscillatory stresses at $37^{\circ} \mathrm{C}$. ${ }^{b} \mathrm{Gel}$ point is the time at which $\mathrm{G}^{\prime}$ becomes equal to $\mathrm{G}^{\prime \prime}$. ${ }^{\mathrm{c}} 0.1 \mathrm{M}$ phosphate buffer's $\mathrm{pH}$.

ed from strain-stress curves using the slope of the linear regression line for strains between 0 and 0.1 . The magnitude of $E$ was significantly dependent on the gelatin concentration; the higher concentration, the higher values of $E$ in the range from 21 to $292 \mathrm{kPa}$ 


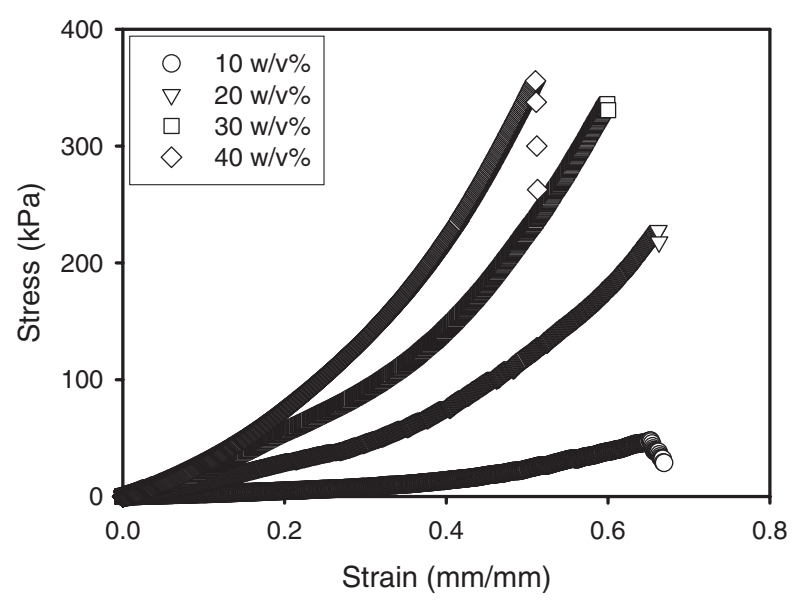

Figure 4. Compressive strain-stress curves of gelatin gels using different gelatin concentration with $0.3 \mathrm{w} / \mathrm{v} \%$ TGase.

Table III. Effect of Gelatin Concentration in the Feed on the Mechanical Properties of TGase-Catalyzed Gels, $n=3^{\text {a }}$

\begin{tabular}{cccc}
\hline $\begin{array}{c}\text { Gelatin } \\
\text { Concentration }(\mathrm{w} / \mathrm{v} \%)\end{array}$ & $E(\mathrm{kPa})$ & $\sigma(\mathrm{kPa})$ & $\lambda(\mathrm{mm} / \mathrm{mm})$ \\
\hline 10 & $21 \pm 2$ & $48 \pm 4$ & $0.35 \pm 0.01$ \\
20 & $127 \pm 7$ & $152 \pm 18$ & $0.43 \pm 0.04$ \\
30 & $229 \pm 3$ & $336 \pm 23$ & $0.40 \pm 0.08$ \\
40 & $292 \pm 12$ & $357 \pm 15$ & $0.49 \pm 0.02$ \\
\hline
\end{tabular}

${ }^{a}$ Mechanical properties (elastic modulus $(E)$, fracture stress $(\sigma)$, and fracture strain $(\lambda)$ ) of gelatin gels prepared by mixing TGase $(0.3 \mathrm{w} / \mathrm{v} \%)$ with different concentration of gelatin.

(Table III). Reorganization of gelatin chains during the gelation also improves the mechanical properties. ${ }^{20}$ Although gelatin is a denatured substance from collagen involving rupture of the triple-helix structure by breaking of hydrogen bonds and rearrangement of the triple-helix into a random configuration, the gelatin chains can undergo a conformational disorder-order transition to form thermoreversible networks by associating the triple-helix structures in junction zones stabilized by hydrogen bonds during the gelation. Thus, the higher concentration of gelatin offers the higher crosslinking sites for chemical and physical crosslinkings.

The effect of the TGase concentration on the mechanical properties of the gelatin gel was investigated. The enhancement in the mechanical strength was observed with the higher concentration of TGase. This is in good agreement with the results of rheological test. The values of $E$ with 0.7 w/v\% TGase multiplied significantly by about 1.5 folds $(132 \mathrm{kPa})$ with respect to that measured with $0.1 \mathrm{w} / \mathrm{v} \%$ TGase (Table IV), indicating that the higher concentration of gelatin and TGase enhances the mechanical properties of the gel, which are predominantly incremented by the cross-linkage of gelatin.
Table IV. Effect of TGase Concentration in the Feed on the Mechanical Properties of Gelatin Gels, $n=3^{\text {a }}$

\begin{tabular}{cccc}
\hline $\begin{array}{c}\text { TGase Concentration } \\
(\mathrm{w} / \mathrm{v} \%)\end{array}$ & $E(\mathrm{kPa})$ & $\sigma(\mathrm{kPa})$ & $\lambda(\mathrm{mm} / \mathrm{mm})$ \\
\hline 0.1 & $91 \pm 8$ & $141 \pm 16$ & $0.34 \pm 0.07$ \\
0.2 & $100 \pm 11$ & $148 \pm 21$ & $0.44 \pm 0.07$ \\
0.3 & $127 \pm 7$ & $152 \pm 18$ & $0.43 \pm 0.04$ \\
0.4 & $127 \pm 5$ & $188 \pm 14$ & $0.38 \pm 0.03$ \\
0.5 & $130 \pm 8$ & $224 \pm 16$ & $0.32 \pm 0.06$ \\
0.7 & $132 \pm 5$ & $287 \pm 9$ & $0.28 \pm 0.03$ \\
\hline
\end{tabular}

${ }^{a}$ Mechanical properties (elastic modulus $(E)$, fracture stress $(\sigma)$, and fracture strain $(\lambda)$ ) of gelatin gels prepared by mixing gelatin $(20 \mathrm{w} / \mathrm{v} \%)$ with different concentration of TGase.

\section{Degree of Crosslinking of Gelatin Gels}

The mechanical property of the gelatin gels can be modulated by the extent of crosslinking by TGase. The residual primary amino group in the crosslinked sample was determined as a measure of the degree of crosslinking to elucidate the relationships of the mechanical strength of gelatin gels. ${ }^{17}$ In this study, the degree of crosslinking is defined as a percentage of the free amino groups in the cross-linked samples related to the non-cross-linked sample. The amino acid composition of gelatins from cold water fish such as cod and hake was previously reported. ${ }^{5}$ The content of lysine (including hydroxylysine) and glutamate (glutamine and glutamic acid) was about 3.5 and $7.8 \%$.

The effect of the gelatin concentrations on the degree of crosslinking was examined. As the gelatin concentration increased, the extent of the crosslinking of the terminal amino groups in gelatin increased between 5.2 and $28.5 \%$ (Figure 5). These values are comparable with those of the reported enzymatically cured gelatin gels and smaller than those of the chemically crosslinked gels. The degree of crosslinking with different TGase concentration was also measured. The increase of crosslinking degree was observed in the use of the higher concentration of TGase. These data indicate that large content of the enzymatically crosslinkable groups (e.g. lysine and glutamine residues) and catalysts can provide many chances for the crosslinking reaction, leading to polymeric networks having the high degree of crosslinking. ${ }^{16 a}$ Resultingly, the higher degree of crosslinking induces the higher mechanical strength of gelatin gel as shown in Tables III and IV, and Figure 5.

\section{CONCLUSIONS}

Gelatin from cold water fish has a much higher critical concentration and lower melting point than mammalian samples, resulting in their limited applications. 

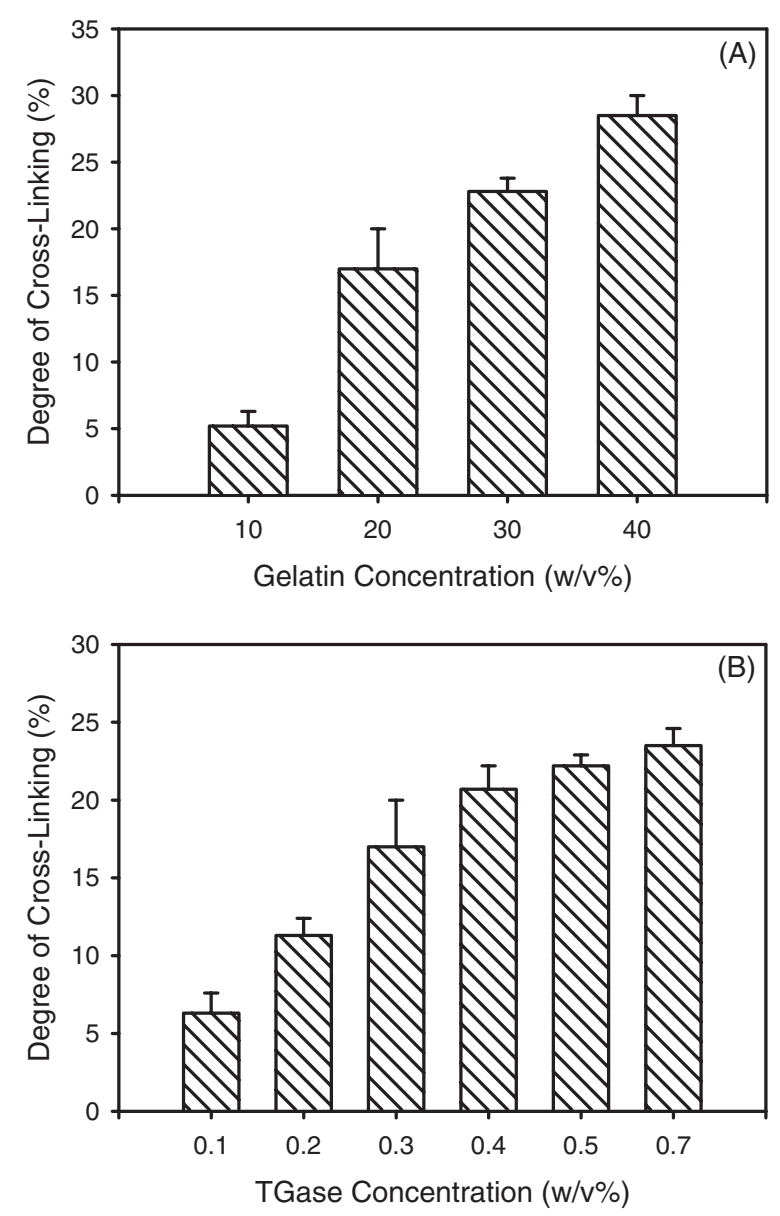

Figure 5. Degree of crosslinking of gelatin gels using (A) different gelatin concentration with $0.3 \mathrm{w} / \mathrm{v} \%$ TGase and (B) different TGase concentration with $20 \mathrm{w} / \mathrm{v} \%$ gelatin, expressed as the percentage of primary amine group content lost after crosslinking, $n=3$.

This is due to the lower hydroxyproline content, which in turn reduces the propensity for intermolecular helix formation. TGase provides an alternative method for creating hydrogels of gelatin from cold water fish and may offer interesting opportunities as injectable material for various applications. In the present study, we have found that non-toxic, biocompatible and biodegradable hydrogels can be constructed from cold water fish gelatins with the enzyme catalyst. The rapid crosslinking of gelatin takes place in the presence of TGase to fabricate a biocompatible hydrogel. Interestingly, the mechanical properties of the product gels were greatly affected by the concentration of gelatin and TGase and closely connected with the degree of crosslinking. The systematic data of the TGase-catalyzed curing of fish gelatin obtained in this study are useful for bio-related applications of fish gelatin. Furthermore, we believe that there are several potential benefits of these enzymatic approaches such as no use of toxic chemical crosslinking agents and mild reaction conditions.

\section{REFERENCES}

1. P. I. Ross, in "Encyclopedia of Polymer Science and Engineering," vol 7, H. F. Mark, N. M. Bikales, C. G. Overberger and G. Menges, Ed., Wiley, New York, 1987, p 488.

2. a) G. A. Digenis, T. B. Gold, and V. P. Shah, J. Pharm. Sci., 83, 915 (1994).

b) E. Esposito, R. Cortesi, and C. Nastruzzi, Biomaterials, 20, 2009 (1995).

c) Y. Otani, Y. Tabata, and Y. Ikada, Biomaterials, 19, 2091 (1998).

3. a) K. Yoshimura, M. Terashima, D. Hozan, T. Ebato, Y. Nomura, Y. Ishii, and K. Shirai, J. Agric. Food Chem., 48, 2023 (2000).

b) D. Swatschek, W. Schatton, W. Muller, and J. Kreuter, Eur. J. Pharm. Biopharm., 53, 125 (2002).

4. P. M. Gilsenan and S. B. Ross-Murphy, Food Hydrocolloids, 14, 191 (2000).

5. M. C. Gómez-Guillén, J. Turnay, M. D. Fernández-Díaz, N. Ulmo, M. A. Lizarbe, and P. Montero, Food Hydrocolloids, 16, 25 (2002).

6. a) N. A. Peppas, in "Biomaterials Science: An Introduction to Materials in Medicine," B. D. Ratner, A. S. Hoffman, F. J. Schoen, and J. E. Lemons, Ed., Academic Press, San Diego, 1996, p 60.

b) J. P. Gong, T. Kurokawa, T. Narita, G. Kagata, Y. Osada, G. Nishimura, and M. Kinjo, J. Am. Chem. Soc., 123, 5582 (2001).

c) A. Kakugo, S. Sugimoto, J. P. Gong, and Y. Osada, $A d v$. Mater., 14, 1124 (2002).

7. a) A. Martinsen, G. Skjak-Braek, and O. Smidsrod, Biotechnol. Bioeng., 33, 79 (1989).

b) S. W. Shalaby and K. Park, in "Biomedical Polymers: Designed to Degrade Systems," chap. 9, S. W. Shalaby, Ed., Hanser Publishers, Munich, 1994, p 213.

c) S. H. Kim, C. Y. Won, and C. C. Chu, J. Biomed. Mater. Res., 46, 160 (1999).

d) T. Chen, H. D. Embree, E. M. Brown, M. M. Taylor, and G. F. Payne, Biomaterials, 24, 2831 (2003).

e) Y. Tachibana, M. Kurisawa, H. Uyama, T. Kakuchi, and S. Kobayashi, Chem. Lett., 32, 374 (2003).

f) Y. Takeuchi, H. Uyama, N. Tomoshige, E. Watanabe, Y. Tachibana, and S. Kobayashi, J. Polym. Sci., Part A: Polym. Chem., 44, 671 (2006).

8. K. Y. Lee and D. J. Mooney, Chem. Rev., 101, 1869 (2001).

9. A. J. Kuijpers, G. H. M. Engbers, J. Krijgsveld, S. A. Zaat, J. Dankert, and J. Feijen, J. Biomater. Sci., Polym. Ed., 11, 225 (2000).

10. D. P. Speer, M. Chavapil, C. D. Eskelson, and J. Ulreich, J. Biomed. Mater. Res., 14, 753 (1980).

11. a) J. P. Draye, B. Delaey, A. Van de Voorde, A. Van Den Bulke, B. Bogdanov, and E. Schacht, Biomaterials, 19, 99 (1998).

b) K. Y. Lee, K. H. Bouhadir, and D. J. Mooney, Macromolecules, 33, 97 (2000).

12. H. L. Fuchsbauer, U. Gerber, J. Engelmann, T. Seeger, C. Sinks, and T. Hecht, Biomaterials, 17, 1481 (1996). 
13. P. M. Nielsen, Food Biotech., 9, 119 (1995).

14. J. J. Pisano, J. S. Finlayson, and M. P. Peyton, Science, 160, 892 (1968).

15. M. Motoki and K. Seguro, Trends Food Sci. Technol., 9, 204 (1998).

16. a) V. Crescenzi, A. Francescangeli, and A. Taglienti, Biomacromolecules, 3, 1384 (2002).

b) M. K. McDermott, T. Chen, C. M. Williams, K. M. Markley, and G. F. Payne, Biomacromolecules, 5, 1270 (2004).

17. M. T. Sheu, J. C. Huang, G. C. Yeh, and H. O. Ho, Biomaterials, 22, 1713 (2001).
18. a) A. H. Clark and S. B. Ross-Murphy, Adv. Polym. Sci., 83, 58 (1987).

b) H. H. Winter and M. Mours, Adv. Polym. Sci., 134, 165 (1997).

19. a) J. Bailey and D. Ollis, in "Biochemical engineering fundamentals," 2nd ed., McGraw-Hill, New York, 1986.

b) A. S. Eissa, S. Bisram, and S. A. Khan, J. Agric. Food Chem., 52, 4456 (2004).

20. a) I. Pezron, M. Djabourov, and J. Leblond, Polymer, 32, 3201 (1991).

b) S. B. Ross-Murphy, Polymer, 33, 2622 (1992). 